University of Wollongong

Research Online

Australian Institute for Innovative Materials -

Papers

Australian Institute for Innovative Materials

2013

Nanoscale platinum printing on insulating substrates

C D. O'Connell

University of Wollongong, coc531@uowmail.edu.au

M J. Higgins

University of Wollongong, mhiggins@uow.edu.au

R P. Sullivan

University of Wollongong, rps759@uowmail.edu.au

S S. Jamali

University of Wollongong, ssj198@uowmail.edu.au

S E. Moulton

University of Wollongong, smoulton@uow.edu.au

See next page for additional authors

Follow this and additional works at: https://ro.uow.edu.au/aiimpapers

Part of the Engineering Commons, and the Physical Sciences and Mathematics Commons

Research Online is the open access institutional repository for the University of Wollongong. For further information contact the UOW Library: research-pubs@uow.edu.au 


\title{
Nanoscale platinum printing on insulating substrates
}

\author{
Abstract \\ The deposition of noble metals on soft and/or flexible substrates is vital for several emerging \\ applications including flexible electronics and the fabrication of soft bionic implants. In this paper, we \\ describe a new strategy for the deposition of platinum electrodes on a range of materials, including \\ insulators and flexible polymers. The strategy is enabled by two principle advances: (1) the introduction of \\ a novel, low temperature strategy for reducing chloroplatinic acid to platinum using nitrogen plasma; (2) \\ the development of a chloroplatinic acid based liquid ink formulation, utilizing ethylene glycol as both ink \\ carrier and reducing agent, for versatile printing at nanoscale resolution using dip-pen nanolithography \\ (DPN). The ink formulation has been printed and reduced upon Si, glass, ITO, Ge, PDMS, and Parylene C. \\ The plasma treatment effects reduction of the precursor patterns in situ without subjecting the substrate \\ to destructively high temperatures. Feature size is controlled via dwell time and degree of ink loading, and \\ platinum features with $60 \mathrm{~nm}$ dimensions could be routinely achieved on Si. Reduction of the ink to \\ platinum was confirmed by energy dispersive $x$-ray spectroscopy (EDS) elemental analysis and $x$-ray \\ diffraction (XRD) measurements. Feature morphology was characterized by optical microscopy, SEM and \\ AFM. The high electrochemical activity of individually printed Pt features was characterized using \\ scanning electrochemical microscopy (SECM). \\ Keywords \\ insulating, substrates, platinum, nanoscale, printing \\ Disciplines \\ Engineering | Physical Sciences and Mathematics \\ Publication Details \\ O'Connell, C. D., Higgins, M. J., Sullivan, R. P., Jamali, S. S., Moulton, S. E. \& Wallace, G. G. (2013). \\ Nanoscale platinum printing on insulating substrates. Nanotechnology, 24 (50), 1-11. \\ Authors \\ C D. O'Connell, M J. Higgins, R P. Sullivan, S S. Jamali, S E. Moulton, and G G. Wallace
}

This journal article is available at Research Online: https://ro.uow.edu.au/aiimpapers/961 


\title{
Nanoscale platinum printing on insulating substrates
}

\author{
C D O'Connell, M J Higgins*, R P Sullivan, S S Jamali, S E Moulton \\ and G G Wallace*. \\ ARC Centre of Excellence for Electromaterials Science \\ Intelligent Polymer Research Institute \\ Innovation Campus \\ University of Wollongong \\ NSW 2522 (Australia) \\ *Corresponding authors: \\ E-mail: mhiggins@uow.edu.au \\ E-mail: gwallace@uow.edu.au
}

\begin{abstract}
The deposition of noble metals on soft and/or flexible substrates is vital for several emerging applications including flexible electronics and the fabrication of soft bionic implants. In this article, we describe a new strategy for the deposition of platinum electrodes on a range of materials, including insulators and flexible polymers. The strategy is enabled by two principle advances: 1 ) the introduction of a novel, low-temperature strategy for reducing chloroplatinic acid to platinum using nitrogen plasma; 2) the development of a chloroplatinic acid based liquid ink formulation, utilising ethylene glycol as both ink carrier and reducing agent, for versatile printing at nanoscale resolution using dip-pen nanolithography (DPN). The ink formulation has been printed and reduced upon Si, glass, ITO, Ge, PDMS, and Parylene $\mathrm{C}$. The plasma treatment effects reduction of the precursor patterns in situ without subjecting the substrate to destructively high temperatures. Feature size is controlled via dwell time and degree of ink loading, and platinum features with 60 $\mathrm{nm}$ dimensions could be routinely achieved on $\mathrm{Si}$. Reduction of the ink to platinum was confirmed by Energy dispersive X-ray spectroscopy (EDS) elemental analysis and X-Ray Diffraction (XRD) measurements. Feature morphology was characterized by optical microscopy, SEM and AFM. The high electrochemical activity of individually printed Pt features was characterized using Scanning Electrochemical Microscopy (SECM).
\end{abstract}

PACS: 81.07.-b Nanoscale materials and structures: fabrication and characterization; 81.16.Nd Micro- and nanolithography; 81.16.Rf Micro- and nanoscale pattern formation; 82.30.Lp Decomposition reactions (pyrolysis, dissociation, and fragmentation); 85.40.Sz Deposition technology.

\section{Introduction}

Nanoscale metal structures are used in a wide range of applications from integrated circuits, to biosensors and catalysis[1-3]. Platinum, in particular, is the material of choice for the stimulating electrodes in bionic implants[4]. Metallic patterns are conventionally fabricated on rigid substrates using techniques such as electron beam lithography (EBL), photolithography, contact printing, and nanoimprint lithography (NIL)[5]. However, several 
emerging applications, including flexible electronics and bionic (or bioelectronic) implants require patterned metal structures on soft and/or flexible substrates, for which traditional fabrication techniques may not be applicable[6-9]. For instance, polymeric substrates are typically non-conducting, and so electroless deposition methods must be used[10]. The polymeric substrate may also be sensitive to temperature, precluding deposition via high temperature evaporation, and meaning that any curing of the metal must be performed under mild conditions. A popular strategy is to print the metal in the desired pattern in the form of a processable, precursor 'ink', and to subsequently convert the ink to solid metal in situ[1113]. Conductive inks have traditionally been formulated for techniques, such as ink-jet printing, restricted to micro-scale resolution.

Recently, several new techniques have been introduced which extend the printing method into the nano-domain.In electrohydrodynamic (or e-jet) printing, an electrohydrodynamically induced fluid flows through fine microcapillary nozzle is used to achieve resolution which far exceeds that of piezo-electrically driven ink-jet printing[14]. The application of this technique from the tip of an atomic force microscope enables even higher resolution and low applied voltages[15]. The AFM based 'nanofountain' technique allows for dispensation of liquid droplets in the nanoscale regime, though the nanochannel through which the liquid flows may be liable to clogging[16,17].

Dip-pen nanolithography (DPN) is a direct-write lithography technique which uses an atomic force microscope (AFM) tip to deposit a range of 'inks' including organic molecules[18], biomolecules[19,20], and electroactive materials.[21-24] Although a slew of methodologies have been developed over the past decade to print gold features via DPN (see reference [25] for a review of DPN metal printing), very few groups have succeeded in depositing platinum at nanoscales. In one interesting approach, an electrochemical fountain pen was used to create free-standing platinum micro- and nano-structures[1,26]. Although capable of creating intricate 3D structures, this strategy necessitates a conducting or semi-conducting substrate. In addition, significant engineering challenges (such as electrical addressability of the pens, nanofluidic ink delivery) would need to be surmounted to upscale the process. An electroless deposition methodology for nanoscale platinum printing was described in a US patent, though a potentially destructive high temperature reduction step was required[27]. More recently, the Mirkin group adapted 'block copolymer lithography' for the DPN technique[28]. Their ink was based on block-copolymer micelles loaded with metal ions $\left(\mathrm{AuCl}_{4}{ }^{-}\right.$or $\left.\mathrm{HPtCl}_{6}{ }^{-}\right)$. After printing of the micellar solution, an oxygen plasma treatment effected reduction of the metal ions via a hydrocarbon oxidation mechanism. Although a clever avenue towards the placement of individual nanoparticles, the micellar ink contains a very low metal loading, and so is not amenable to fabrication of solid state circuit elements.

In this article, we describe a new strategy for the deposition of nanoscale platinum features on insulators using dip-pen nanolithography. The major novelty is that this nanofabrication strategy requires neither electrical bias, nor a high temperature reduction step. The methodology is thus amenable to high-resolution printing on a range of materials, including flexible polymers and even a human hair. To achieve this, two principle advances were made: 1) the introduction of nitrogen plasma treatment as a low-temperature strategy for reducing chloroplatinic acid to platinum in the absence of micellar ligands; 2) the development of a chloroplatinic acid based liquid ink formulation for DPN, utilising ethylene glycol as both ink carrier and reducing agent. In this paper, we will first discuss the development of the methodology before characterizing the nanoscale printing by DPN. 


\section{Experimental}

\subsection{Materials}

Ethylene glycol and the metal precursors $\mathrm{H}_{2} \mathrm{PtCl}_{6} \cdot \mathrm{x} \mathrm{H}_{2} \mathrm{O}$ and $\mathrm{HAuCl}_{3} \cdot \mathrm{xH} 2 \mathrm{O}$ were obtained from Sigma-Aldrich.

\subsection{Substrate preparation}

Silicon wafer $(\mathrm{Si} / \mathrm{SiOx})$ and glass substrates were cleaned by water bath sonication for 10 min each in isopropanol, acetone, and Milli-Q water.

\subsection{Dropcast thin films}

In a typical experiment, a small volume $(<5 \mu \mathrm{L})$ of metal precursor solution was drop cast onto a clean glass substrate. Films were dropcast from a range of precursor concentrations $(4-40 \% \mathrm{wt})$ in both water and ethylene glycol. Plasma treatment $\left(\mathrm{O}_{2}\right.$ or $\left.\mathrm{N}_{2}\right)$ was performed for 5 or 10 minutes.

\subsection{Patterning methodology}

DPN patterning was performed using an Nscriptor system (NanoInk) in an environment controlled at $45 \%$ relative humidity and $22^{\circ} \mathrm{C}$ temperature (unless otherwise stated). The metal precursor ink (formulation discussed in section 3.1) was wetted onto a single tip (hereafter 'DPN-tip') of NanoInk M-Type probes by dipping for five seconds into the microwell of a NanoInk Universal Inkwell. The M-Type probes (material $\mathrm{Si}_{3} \mathrm{~N}_{4}$, length 107 $\mu \mathrm{m}$, width $22 \mu \mathrm{m}$, spring constant $0.5 \mathrm{~N} / \mathrm{m}$ ) have an ink reservoir etched into the underside of the cantilever, and this holds the ink in place to feed the tip during writing. The tip was bled of excess ink in a method similar to that previously reported for DPN of liquid inks by bringing it in contact with the substrate in several (typically 4-5) locations, until deposition of large $\sim 10 \mu \mathrm{m}$ 'bleed-spots' ceased[22,23,29]. All patterns were generated using the InkCAD software (v 2.7.1) provided with the Nscriptor system. The dwell time dependence of the ink was calibrated by printing arrays of dots using dwell times ranging $0.002 \mathrm{~s}, 0.01 \mathrm{~s}$, $0.05 \mathrm{~s}, 0.1 \mathrm{~s}, 0.25 \mathrm{~s}, 0.5 \mathrm{~s}, 1 \mathrm{~s}, 2 \mathrm{~s}, 3 \mathrm{~s}$ and $5 \mathrm{~s}$. After DPN printing, the substrate was removed for immediate plasma treatment unless otherwise stated. In some experiments time was allowed (24 hours) after DPN printing for evaporation of ethylene glycol before the plasma reduction step was performed.

\subsection{Plasma reduction}

The plasma reduction step was performed in a Harrick Expanded Plasma Cleaner at 1100 mTorr on high power setting $(29.6 \mathrm{~W})$. The plasma species were controlled by feeding $\mathrm{N}_{2}$, $\mathrm{O}_{2}$ or air into the chamber at the desired pressure. A range of plasma times, $30 \mathrm{~s}$ to 40 minutes was investigated. 10 minutes plasma treatment was found to ensure complete reduction of the precursor and was used for all experiments unless otherwise stated.

\subsection{Electrical properties}

Confirmation of electrical conductivity was performed by depositing large $(\sim 10 \mu \mathrm{m})$ 'bleed spots' of platinum precursor ink between planar electrodes, and reducing the ink with $\mathrm{N}_{2}$ plasma treatment. The planar electrodes were defined by standard photolithographic processes and were composed of platinum $(100 \mathrm{~nm})$ on glass with a $10 \mathrm{~nm}$ titanium adhesion layer. The gaps between planar electrodes were $5 \mu \mathrm{m}$ or $10 \mu \mathrm{m}$. After plasma reduction, the current flowing through the resulting platinum resistor was measured using a potentiostat (eDAQ EA162) to drive a linear voltage sweep from $-10 \mathrm{~V}$ to $+10 \mathrm{~V}$. AFM scans of the feature were used to obtain cross-sectional information to calculate resistance. A similar methodology has been followed previously[23]. 
Scanning electrochemical microscopy (SECM) was performed using a 920D CH instruments SECM by raster scanning an SECM tip inset with a $10 \mu \mathrm{m}$ diameter platinum microelectrode over printed platinum features. Feedback mode of SECM was utilized in aqueous $1 \mathrm{mM}$ ferrocenemethanol as redox electron mediator and $0.1 \mathrm{KCl}$ as supporting electrolyte. The tip was held at $+0.4 \mathrm{~V}(\mathrm{Ag} / \mathrm{AgCl})$ at which ferrocene $(\mathrm{FC})$ is oxidized to ferrocenium $\left(\mathrm{FC}^{+}\right)$. The ferrocenium is reduced back to ferrocene in contact with an electrochemically active surface which increases the feedback effect and the current. Current was measured at a constant zheight of $3 \mu \mathrm{m}$ and an 'increment time' of $0.04 \mathrm{~s}$ on a point by point basis over the scan area. The distance between points, determining the scan resolution, was typically $1 \mu \mathrm{m}$.

\subsection{Microscopy}

Optical microscopy images were taken on a Leica DM6000 microscope. Atomic force microscopy (AFM) topographic imaging was acquired with an Nscriptor AFM system (Pacific Nanotechnology) or MFP-3D AFM system (Asylum Research) in intermittent contact mode in air at room temperature. Scanning electron microscopy was performed on a JEOL 7500FA Field Emission Scanning Electron Microscope (FESEM).

\section{Results and discussion}

\subsection{Ink Development}

Under ambient conditions $\mathrm{H}_{2} \mathrm{PtCl}_{6}$ thermally reduces to platinum metal at $500{ }^{\circ} \mathrm{C}[30]$. When dissolved in a reducing agent, such as ethylene glycol, the temperature of reduction is lowered significantly[31-33]. Ethylene glycol also has a relatively low volatility (boiling point $197^{\circ} \mathrm{C}$ ), an important parameter for DPN ink formulations [29]. Cho et al. have shown that thin films of platinum nanoparticles could be formed by simply drop-casting $\mathrm{H}_{2} \mathrm{PtCl}_{6} / \mathrm{EG}$ solution onto a substrate heated to $160{ }^{\circ} \mathrm{C}[32]$. Due to the poor thermal stability of prospective soft and flexible substrates, we set out to develop a mild reduction strategy which did not require high-temperature heating.

Oxygen plasma treatment has recently been used to effect reduction of metal precursors in block copolymer lithography[28]. Block-copolymer micelles loaded with metal ions $\left(\mathrm{AuCl}_{4}{ }^{-}\right.$ or $\mathrm{HPtCl}_{6}{ }^{-}$) were treated with oxygen plasma treatment and reduction of the metal ions occurred via a proposed hydrocarbon oxidation mechanism. This approach has been adapted for DPN, in a technique dubbed scanning-probe block-copolymer lithography (SPBCL)[28]. Although the SPBCL methodology has enabled the in situ synthesis of individual nanoparticles in predefined and arbitrary geometries, the low levels of metal precursor loading preclude its fabrication of more continuous structures, such as connecting wires or circuit elements.

We investigated the in-situ reduction of a simpler metal precursor/ethylene glycol solution, without a block copolymer component. We found that thin films dropcast from $\mathrm{H}_{2} \mathrm{PtCl}_{6} / \mathrm{EG}$ solutions were not reduced by oxygen plasma. The drop-cast film emerged from the plasma chamber as a dried film of red/brown salt (data not shown). However, when nitrogen plasma was used, the drop-cast $\mathrm{H}_{2} \mathrm{PtCl}_{6} / \mathrm{EG}$ thin film formed a shiny, metallic layer. Figure $1 \mathrm{~A}$ shows an optical image of metal films formed on PDMS after $\mathrm{N}_{2}$ plasma treatment of metal precursor solutions. Both gold (at left, from $\mathrm{HAuCl}_{3} / \mathrm{EG}$ solution) and platinum (at right, from $\mathrm{H}_{2} \mathrm{PtCl}_{6} / \mathrm{EG}$ solution) are shown. The PDMS substrate was undamaged by the treatment and maintained its flexibility. Figure $1 \mathrm{~B}$ and $\mathrm{C}$ show optical microscopy images of a $\mathrm{H}_{2} \mathrm{PtCl}_{6} / \mathrm{EG}$ film on glass after 10 minutes $\mathrm{N}_{2}$ plasma treatment. The film appears as an almost continuous metallic sheet, with some gaps filled by micron-scale particles. The presence of grain boundaries indicate that the metal sheet may have formed via a mechanism of mutilnucleated crystal growth during the reduction step. 


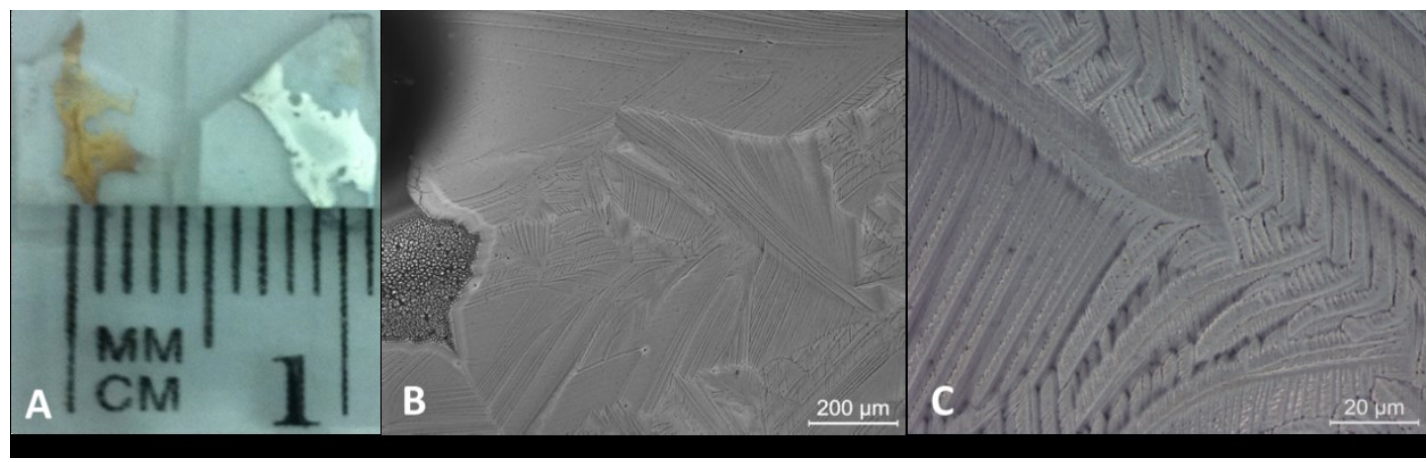

Figure 1: Optical characterisation of drop-cast metal precursor/EG films after $\mathbf{N}_{2}$ plasma treatment; A) Photograph of two PDMS substrates coated with films of gold (left) and platinum (right). $5 \mu \mathrm{L}$ of $10 \%$ (wt) metal precursor solutions in ethylene glycol were dropcast on PDMS and the films were subsequently $N_{2}$ plasma treated for 5 minutes to reduce the precursor solution to metal. (B) Bright field optical micrographs of an area of a plasma treated platinum film on glass. Most of the platinum in the image is composed of one solid metal sheet, though grain boundaries within the metal sheet are evident. The dark area at the left of the image is the film edge; $C$ ) bright field x100 magnification of a single grain boundary.

SEM imaging of the $\mathrm{H}_{2} \mathrm{PtCl}_{6} / \mathrm{EG}$ film revealed two principle material phases in the nanoscale structure. Most of the film was composed of continuous sheets of conductive material (Figure 2 A). Energy dispersive X-ray spectroscopy (EDS) of the sheets indicates them to be composed principally of platinum (Figure $2 \mathrm{C}$ ). The lack of a chlorine component suggests this platinum has been reduced to $\mathrm{Pt}^{0}$. The conductive sheets ( $\left.\operatorname{spot} 1\right)$ are separated by small amounts of non-conductive salt microcrystals (spot 2) (Figure $2 \mathrm{~B}$ ). Both chlorine and platinum were present in these microcrystals, as measured by EDS (Figure 2 D). From the intensities of the EDS peak, chlorine and platinum showed were present in a 6:1 molar ratio, suggesting these crystals are non-reduced $\mathrm{H}_{2} \mathrm{PtCl}_{6}$. 

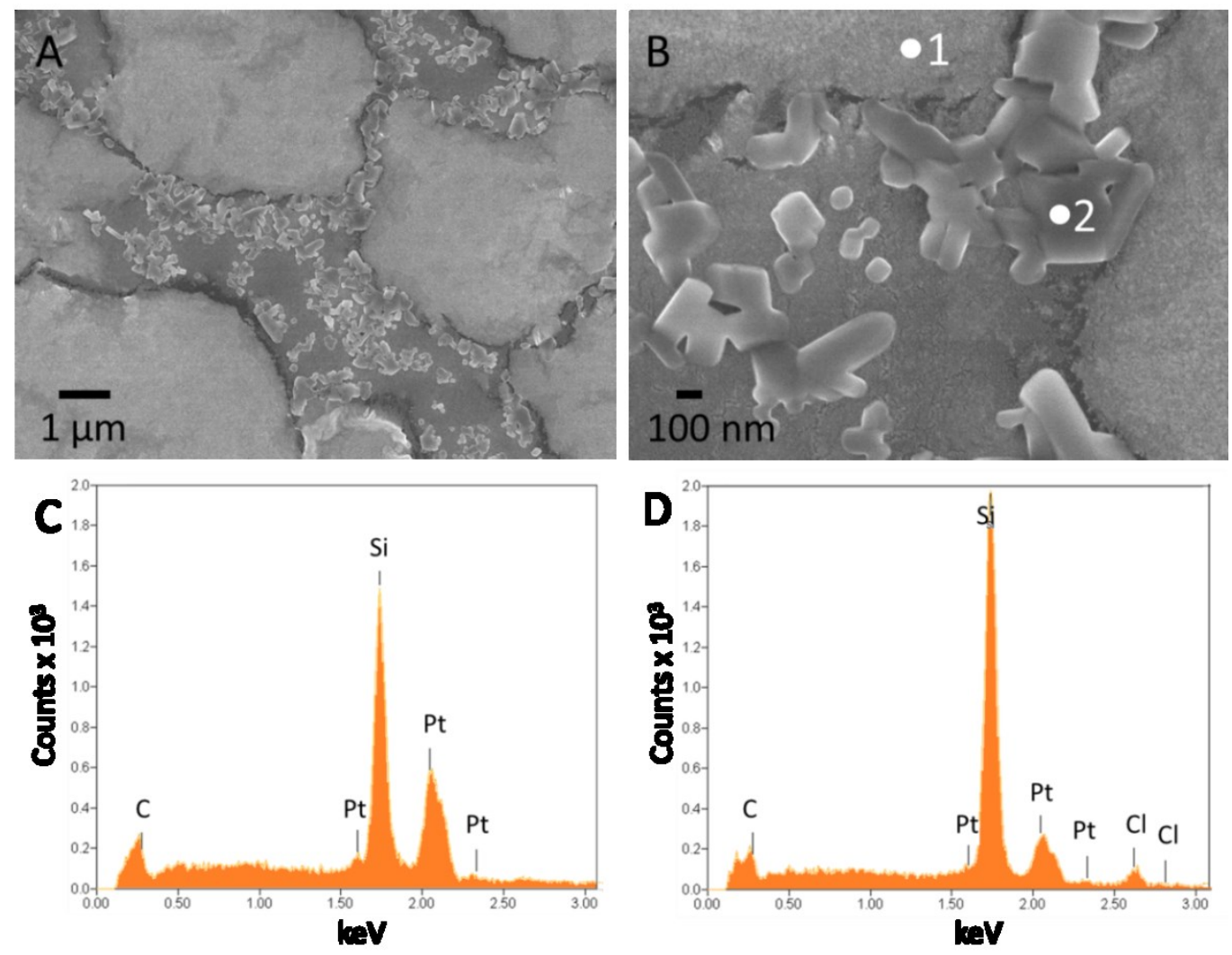

Figure 2: SEM imaging and EDS elemental analysis of a drop-cast $\mathrm{H}_{2} \mathrm{PtCl}_{6} / \mathrm{EG}$ film after $\mathrm{N}_{2}$ plasma treatment: A) A low magnification SEM micrograph shows sheets of platinum metal, surrounded by smaller particles; B) A higher magnification SEM micrograph shows the apparent crystalline nature of the smaller particles. The charging effect during the SEM scan shows the crystals are non-conductive; C) Energy dispersive X-ray spectroscopy (EDS) of the sheet structure indicated by spot 1 in image (B). The EDS spectrum indicates the composition of the island to be mostly platinum, with some carbon contamination, and no chlorine present. The large Si peak comes from the underlying substrate; D) EDS of the microcrystal indicated by spot 2 in image (B) demonstrates the presence of chlorine and platinum in a ratio of 6:1. The microcrystals are likely non-reduced $\mathrm{H}_{2} \mathrm{PtCl}_{6}$.

The reduction of the $\mathrm{H}_{2} \mathrm{PtCl}_{6} / \mathrm{EG}$ drop-cast films to platinum metal was further characterised by X-Ray Diffraction (XRD) measurements on various films drop-cast from $10 \% \mathrm{H}_{2} \mathrm{PtCl}_{6}$ in ethylene glycol. As shown in Figure 3, the $\mathrm{N}_{2}$ plasma treated film and the hotplate heated $\left(300^{\circ} \mathrm{C}\right)$ film exhibit the spectra expected from platinum metal, including peaks at $40.04^{\circ}$ associated with the $\operatorname{Pt}(111)$ face, $46.53^{\circ}$ associated with the $\operatorname{Pt}(200)$ face and $67.86^{\circ}$ associated with the $\operatorname{Pt}(220)$ face. The $\mathrm{O}_{2}$ plasma treated film and the non-treated control film do not exhibit the platinum peaks. The $\mathrm{N}_{2}$ plasma treated film has not undergone complete reduction, however, and small peaks associated with non-reduced precursor crystals are evident at $34^{\circ}, 66^{\circ}$ and $78^{\circ}$. 


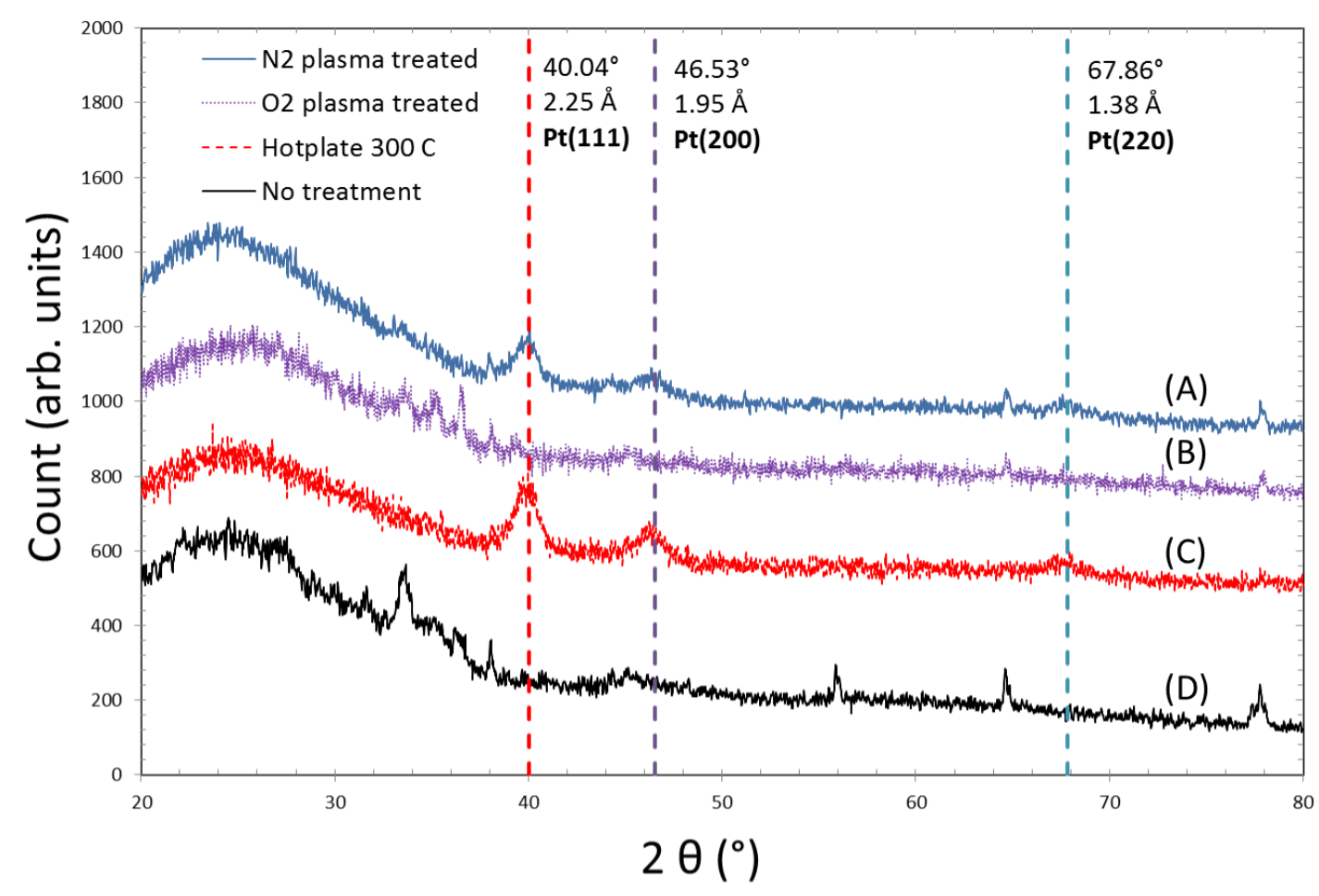

Figure 3: X-Ray Diffraction (XRD) of films formed by dropcasting $10 \% \mathrm{H}_{2} \mathrm{PtCl}_{6}$ in $\mathrm{EG}$ on glass coverslips and then performing differing reduction treatments. The $\mathrm{N}_{2}$ plasma treated film (A) and the hotplate heated $\left(300^{\circ} \mathrm{C}\right)$ film (C) exhibit three clear peaks at scattering angles which correspond to the $\mathrm{Pt}(111), \operatorname{Pt}(200)$ and $\operatorname{Pt}(220)$ faces. The $\mathrm{O}_{2}$ plasma treated film and the non-treated control film do not exhibit the platinum peaks. The peaks at $34^{\circ}, 66^{\circ}$ and $78^{\circ}$. in the untreated film (D) are associated with the precursor salt. (Note: The spectra have been off-set on the vertical axis for clarity.)

The reduction of metal precursor loaded block-copolymer micelles using oxygen plasma has been attributed to a mechanism of hydrocarbon oxidation, however no precise reduction mechanism was elaborated[28,34]. In our case, reduction only takes place using nitrogen or air plasma, and not pure oxygen. It is unclear at present whether a nitrogen plasma species is playing a direct role in the reaction or whether reduction is effected by localised heating only. In our system, dropcast films which were dried out prior to plasma treatment were not reduced to metal, suggesting that the precursor must be solvated for reduction to occur.

The thermal reduction of various metal precursors loaded in a poly(ethylene oxide)-blockpoly(2-vinyl pyridine) (PEO-b-PVP) block-copolymer carrier has been probed by subjecting samples to differing heating cycles[35]. Reduction of each metal precursor was found to follow one of three pathways, depending on the reduction potential of that species. High redox potential species, such as gold and silver, were reduced by the polyethylene oxide (PEO) copolymer at low annealing temperatures $\left(\sim 150^{\circ} \mathrm{C}\right)$. The platinum precursor $\left(\mathrm{H}_{2} \mathrm{PtCl}_{6}\right)$ had to undergo a high temperature annealing step $\left(\sim 500^{\circ} \mathrm{C}\right)$ for reduction to take place, at which temperature the block copolymer carrier also decomposed. This high temperature corresponds to the thermal decomposition temperature of $\mathrm{H}_{2} \mathrm{PtCl}_{6}$ in the absence of a reducing agent[30]. In systems where EG is used as a reducing agent, the thermal reduction temperature of $\mathrm{H}_{2} \mathrm{PtCl}_{6}$ can be as low as $160^{\circ} \mathrm{C}[32]$. The reaction is proposed to proceed via a double-oxidation of EG[31,36]. Thus, localised heating of the substrate to $160^{\circ} \mathrm{C}$ by plasma treatment may be enough to facilitate reduction, as long as the reducing agent is still present. 


\subsection{Developing a methodology for printing platinum precursor solutions by DPN}

DPN experiments were performed on silicon using EG solutions containing a range of metal precursor concentrations (from $10 \%$ to $48 \% \mathrm{wt}$ ). Deposition of each ink in this range was achieved. However, as the most promising for solid state applications we limited our investigation thereafter to the solution with highest platinum loading. Table 1 shows a summary of the liquid properties of the $48 \%$ wt $\mathrm{H}_{2} \mathrm{PtCl}_{6} / \mathrm{EG}$ along with pure $\mathrm{EG}$ and water for comparison.

In preliminary experiments, deposition of the $\mathrm{H}_{2} \mathrm{PtCl}_{6} / \mathrm{EG}$ solution was attempted using hydrophilic (plasma treated) DPN pens. Although deposition was achieved on Si, printing ceased after only 10 deposited features. It was found that diffusion of the ink over the hydrophilic cantilever chip was limiting printing lifetime. Thereafter, all DPN pens were rendered hydrophobic by silanization with octadecyltrimethoxysilane (ODTMS). Pens functionalised with ODTMS had a much longer printing lifetime than non-functionalised pens. The improvement in inking lifetime was characterised by measuring the change in mass of ink on the cantilever with time using its resonant frequency (see Supporting Information).

\begin{tabular}{cccccc}
\hline Solvent & $\begin{array}{c}\mathbf{H}_{2} \mathbf{P t C l}_{\mathbf{6}} \times \mathbf{x H}_{2} \mathbf{O} \\
\text { loading }\end{array}$ & $\begin{array}{c}\text { Density } \\
(\mathbf{g} / \mathbf{m l})\end{array}$ & $\begin{array}{c}\text { Surface } \\
\text { tension } \\
\left(\mathbf{m N ~ m}^{-1}\right)\end{array}$ & \multicolumn{2}{c}{$\begin{array}{c}\text { Macroscopic Contact } \\
\text { angles }\end{array}$} \\
\cline { 5 - 6 } & & & & $\begin{array}{c}\text { Bare } \\
\mathbf{S i} / \mathbf{S i O}_{2}\end{array}$ & $\mathbf{S i}\left(-\mathbf{C H}_{3}\right)$ \\
EG & 0 & 1.104 & 46.93 & 20.2 & 65.1 \\
& & $(0.001)$ & $(0.13)$ & $(1.7)$ & $(3.0)$ \\
EG & $\mathbf{4 7 . 8}$ & $\mathbf{1 . 4 8 4}$ & $\mathbf{5 5 . 9 9}$ & $\mathbf{3 6 . 3}$ & $\mathbf{7 6 . 3}$ \\
& & $\mathbf{( 0 . 0 0 1 )}$ & $\mathbf{( 0 . 3 2 )}$ & $\mathbf{( 0 . 6 )}$ & $\mathbf{( 1 . 7 )}$ \\
$\mathrm{H}_{2} \mathrm{O}$ & 0 & 1.000 & 72.8 & 46 & 91 \\
& & & & $(1.2)$ & $(1.7)$ \\
\hline
\end{tabular}

Table 1: Liquid properties of the $\mathrm{H}_{2} \mathrm{PtCl}_{6}$ solutions and their contact angles with $\mathrm{Si} / \mathrm{SiO}_{2}$ and $\mathrm{Si} / \mathrm{SiO}_{2}$ rendered hydrophobic with octadecyltrimethoxysilane (ODTMS).

\subsection{DPN printing on Silicon}

To investigate the effect of plasma treatment on the morphology of printed patterns, two similar DPN dot arrays of $\mathrm{H}_{2} \mathrm{PtCl}_{6}(48 \% \mathrm{wt})$ in EG were printed on different Si substrates. The first substrate was not plasma treated, and simply allowed to dry over a period of hours. The second substrate was treated with nitrogen plasma for 10 minutes immediately after printing. SEM images of each sample are shown in Figure 4.

The printed features on the non-plasma treated sample formed clusters of dried crystals after evaporation of the EG solvent. EDS of a single crystal confirmed the presence of chlorine and platinum in a molar ratio of $6: 1$, suggesting these are crystals of unreacted $\mathrm{H}_{2} \mathrm{PtCl}_{6}$. The dark circles surrounding each crystal cluster in the non-treated sample are likely a contrast resulting from residual solvent on the substrate, and therefore may indicate the original dimensions of each feature before drying.

The printed features on the plasma treated sample formed discrete metallic dots. EDS confirmed that each feature was composed of platinum, with some carbon contamination and no chlorine. Each printed dot contained one small white region. Higher magnification micrographs revealed the white regions to be cubic in shape; the cube may represent a crystal of $\mathrm{H}_{2} \mathrm{PtCl}_{6}$ being formed at the onset of $\mathrm{EG}$ evaporation, but prior to reduction by nitrogen plasma. This crystal formation highlights the necessity to effect plasma treatment immediately following the printing step in this DPN approach. 


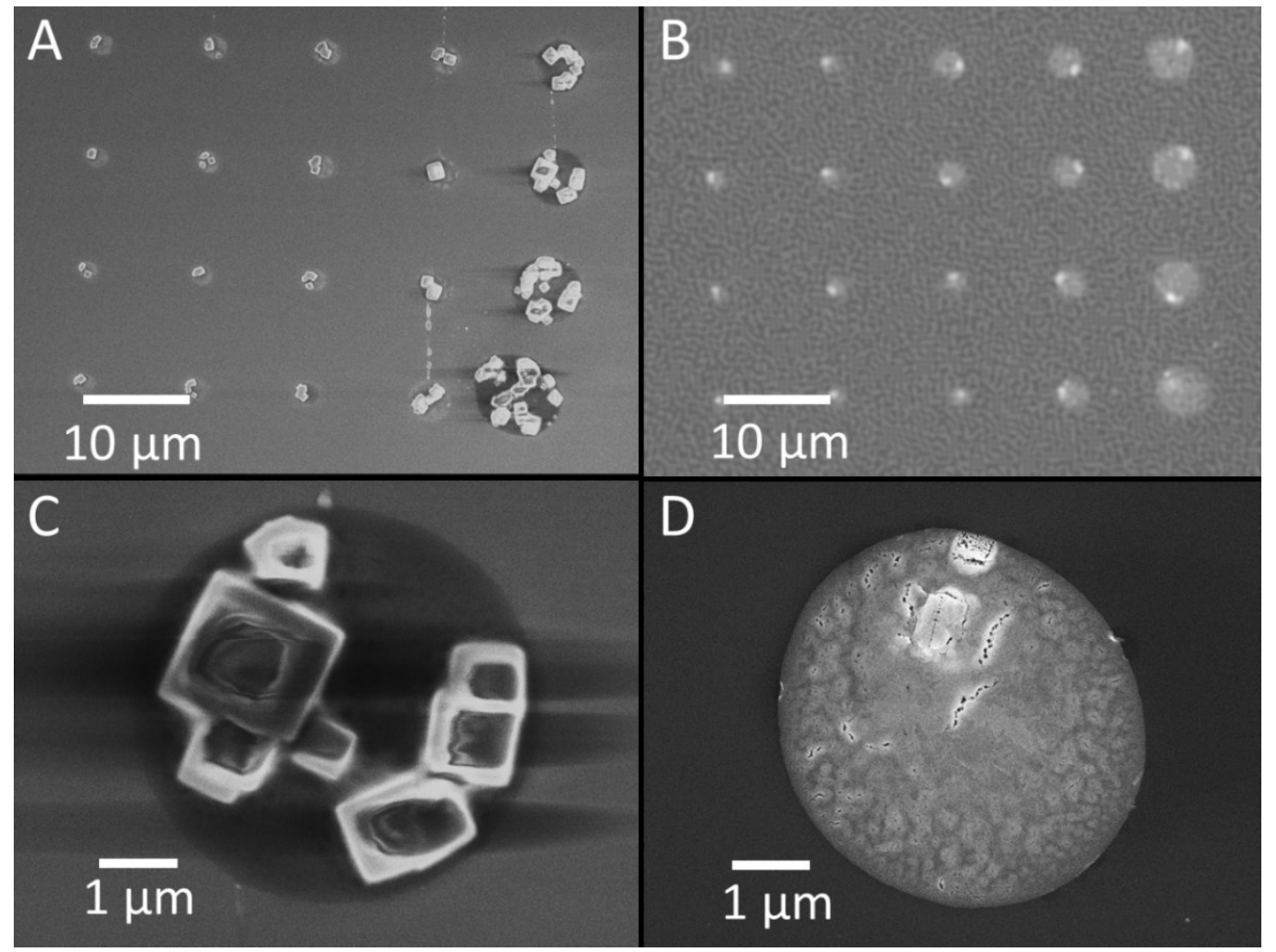

Figure 4: Effect of nitrogen plasma treatment on morphology of $48 \%$ wt $\mathrm{H}_{2} \mathrm{PtCl}_{6} / \mathrm{EG}$ DPN patterns: A) and C) SEM micrographs of $\mathrm{H}_{2} \mathbf{P t C l}_{6} / \mathbf{E G}$ features printed on silicon without subsequent plasma treatment. The printed solution has dried out, forming crystals of hydrated $\mathrm{H}_{2} \mathrm{PtCl}_{6}$. The dark circles around each crystal cluster are likely an SEM contrast resulting from residual solvent on the substrate. EDS of the crystal cluster shown in $(C)$ confirmed platinum and chlorine present in a 1:6 ratio; B) and D) $\mathrm{H}_{2} \mathrm{PtCl}_{6} / \mathrm{EG}$ features on a silicon substrate which was treated with nitrogen plasma immediately after printing. Each feature has reduced to form a solid platinum dot. EDS of the crystal cluster shown in (D) confirmed the feature is made of platinum with no chlorine component.

\subsection{Nanoscale platinum printing on silicon.}

The images in Figure 4 above exhibit micron-scale platinum features. These dots were printed soon after inking the DPN pen, when deposition rate is highly dependent on volume of ink on the cantilever[37]. When a low loading of ink remained on the pen, reproducible nano-scale features were achieved (Figure 5). The dwell time dependence of feature size was investigated within this nano-scale printing regime. Calibration grids, consisting of a series of dots deposited with dwell times ranging from $0.002 \mathrm{~s}$ to $5 \mathrm{~s}$ were printed using the $48 \% \mathrm{wt}$ $\mathrm{H}_{2} \mathrm{PtCl}_{6}$ ink on hydrophobic SiOx (i.e. SiOx fully functionalised with ODTMS, see experimental section). The patterns were reduced by $\mathrm{N}_{2}$ plasma treatment before imaging by SEM. Figure $5 \mathrm{~A}$ and B show a typical dwell-time calibration grid. Feature size increased with dwell time from a minimum of $\sim 60 \mathrm{~nm}$ at $0.002 \mathrm{~s}$ dwell time, to $130 \mathrm{~nm}$ at $5 \mathrm{~s}$ dwell time. As shown in Figure $5 \mathrm{C}$, feature radius exhibits a roughly linear dependence on the square root of dwell time $\left(\mathrm{t}^{1 / 2}\right)$ as is typical for DPN of both molecular and liquid inks $[18,37]$. The slope of this graph, indicative of 'deposition rate', shows that feature radius grows as $\sim 38 \mathrm{~nm} \mathrm{~s}^{-1 / 2}$. The $\mathrm{r}^{1 / 2}$ dependency is not expected to intercept the origin as the minimum achievable feature size is nominally limited by the sharpness of the tip. 
Close inspection of Figure $5 \mathrm{C}$ reveals that the smallest features (printed with dwell time $<0.5 \mathrm{~s}$ ) may follow a slightly different deposition rate than the larger features (dwell time $>0.5 \mathrm{~s}$ ). Although a thorough elucidation of deposition dynamics in this rich system is outside the scope of this paper, we will briefly discuss the various factors which may be at play. A change in deposition rate has been previously observed in DPN of molecular inks, where it was attributed to a transition between two distinct deposition regimes[38]. We cannot assume that a similar phenomenon is at work here, however. The mechanism of material transport from an AFM tip depends on the nature of the ink in question[39]. The ink we have developed in this paper is liquid based and should be analysed in terms of the mechanism of liquid deposition from an AFM tip, rather than molecular diffusion from an AFM tip. Several phenomena unique to liquid deposition may contribute to the transition in deposition rate observed in Figure 5 C. For liquid inks, the volume of ink on the cantilever affects ink flow from tip to substrate[37]. More particularly, the deposition rate depends on the local volume of ink on the tip apex, and ink distribution along the cantilever is subject to dynamic reorganisation during printing[40]. Thus, feature size can be influenced by factors such as the order of dots printed[40]. In our case, the system is rendered more complex as the precursor $\left(\mathrm{H}_{2} \mathrm{PtCl}_{6}\right)$ is also soluble in water. Thus the presence of adsorbed water on the substrate, and the condensation of a water meniscus will also likely contribute to transport rate. Noting that the minimum feature size ( $\sim 60 \mathrm{~nm}$ at $0.002 \mathrm{~s}$ in $45 \% \mathrm{RH})$ is consistent, we have performed our nanoscale printing under these conditions unless otherwise stated.

Figure $5 \mathrm{D}$ shows an example of arbitrary pattern generation, the letters IPRI (for the Intelligent Polymer Research Institute) made from 236 individual $60 \mathrm{~nm}$ radius features at a dot-spacing of $500 \mathrm{~nm}$.

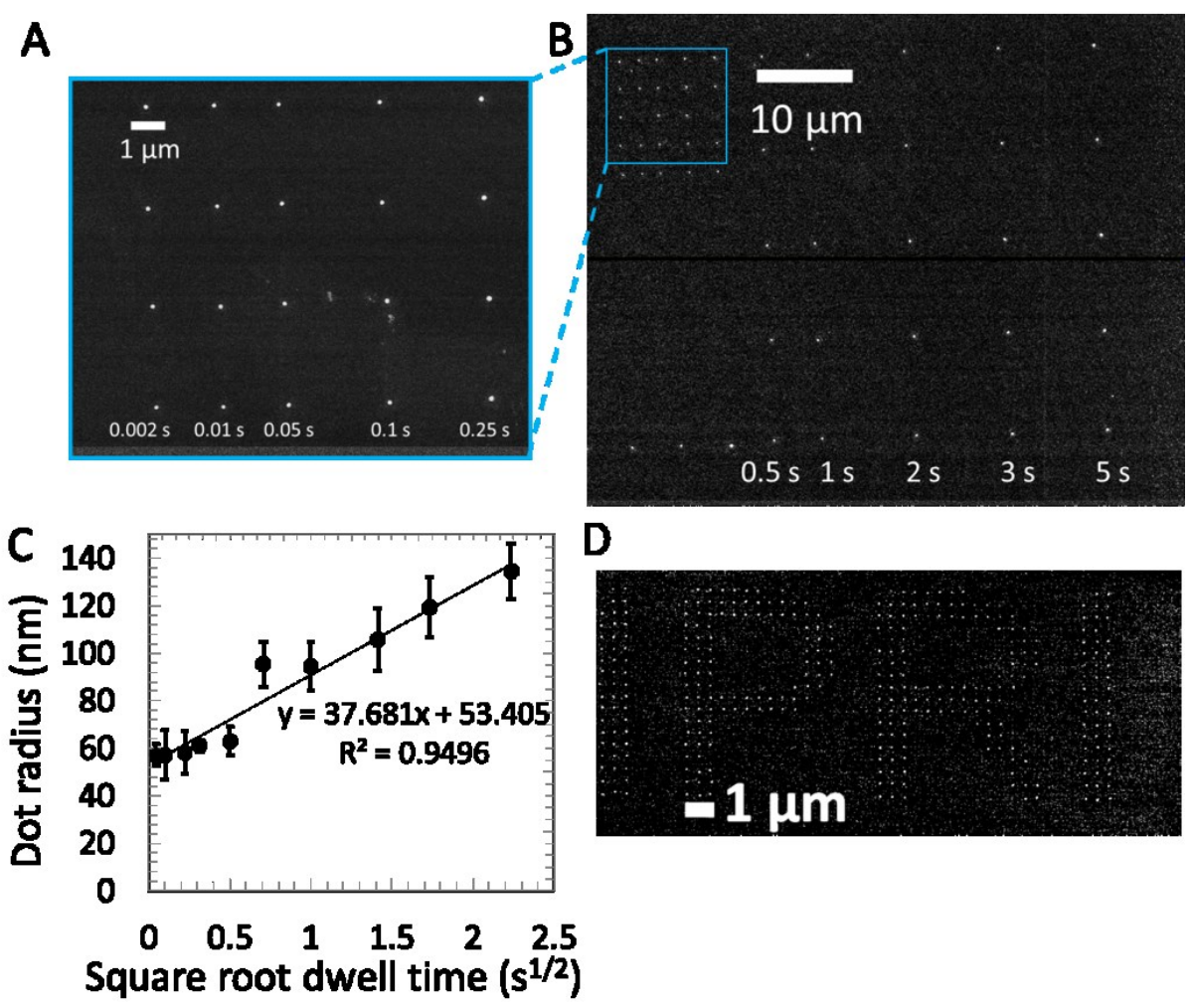

Figure 5: Dot-radius versus dwell time for $48 \% \mathrm{H}_{2} \mathrm{PtCl}_{6}$ in EG: A) SEM micrograph of the shorter dwell time array. Dots deposited with dwell times $0.002 \mathrm{~s}, 0.01 \mathrm{~s}, 0.05 \mathrm{~s}, 0.1 \mathrm{~s}$ and $0.25 \mathrm{~s}$ are indicated; (B) SEM micrograph of a representative dwell-time 
calibration grid, dots deposited with dwell times of $0.5 \mathrm{~s}, 1 \mathrm{~s}, 2 \mathrm{~s}, 3 \mathrm{~s}$ and $5 \mathrm{~s}$ are indicated. Dots deposited with even shorter dwell times can be seen in the small array in the top left corner; C) The plot of dot radius versus square root of dwell time exhibits a linear dependency; D) SEM micrograph of the letters IPRI (for the Intelligent Polymer Research Institute) composed of 236 individual dots of $60 \mathrm{~nm}$ radius, each printed at 0.002 s dwell time.

Although a minimum feature size of $60 \mathrm{~nm}$ was achieved, a limitation was found in that features could not be printed arbitrarily close to one another. Figure 6 (A) shows the InkCAD pattern designed to investigate this effect. The pattern consists of a gradient in dot density with dot-spacing decreasing from $3 \mu \mathrm{m}$ to $250 \mathrm{~nm}$ (from left to right). All dots were printed with a $0.002 \mathrm{~s}$ dwell time. Figure 6 (B) shows a printed dot array generated from this gradient pattern. Consistent dot features of $60 \mathrm{~nm}$ diameter were printed in programmed positions for dot-spacings of $3 \mu \mathrm{m}, 2 \mu \mathrm{m}, 1 \mu \mathrm{m}$, and $500 \mathrm{~nm}$. The inset in Figure 6 (B) shows a magnified image of some features with $500 \mathrm{~nm}$ spacing. It is clear from this image that the linear registry of features was not perfect. This may be due to non-linearity in the piezo-electric positioning system, or due to settling of ink-droplets at energetically favourable positions during deposition (e.g. due to contact line pinning at defect sites). Deposition was successful fot all features at $3 \mu \mathrm{m}, 2 \mu \mathrm{m}$ and $1 \mu \mathrm{m}$ spacing ( $\mathrm{n}=64)$, and was $91 \%$ successful for spacing of $500 \mathrm{~nm}(\mathrm{n}=305)$. We noticed that the success rate in deposition decreased over the course of a long print run. Our group has recently shown how deposition dynamics in liquid ink deposition from an AFM tip can change as a result of decreased volume of ink on the cantilever[37]. The ink available at the tip apex is also liable to reorganise during printing, which may explain why some dots print and some do not[40]. Future AFM based deposition methods could measure cantilever deflection for in situ monitoring and correction of deposition errors[37].

As shown in Figure 6 (B), no features were deposited at a $250 \mathrm{~nm}$ spacing. We suggest this lack of deposition is due to the ink transport meniscus overlapping with previously deposited features and interfering with any previously deposited ink. Thus no pattern could be defined. This 'proximity limit' appears to be a limitation of the technique and arises because the deposited features are still in their precursor $\left(\mathrm{H}_{2} \mathrm{PtCl}_{6}\right)$ form, and therefore resoluble in the liquid meniscus. In order to rule out the influence of the water meniscus formed by capillary condensation between an AFM tip and the substrate[41], the proximity limit experiment was repeated at low (5\% relative humidity). The same $500 \mathrm{~nm}$ proximity limit was found for depositing discrete features. 


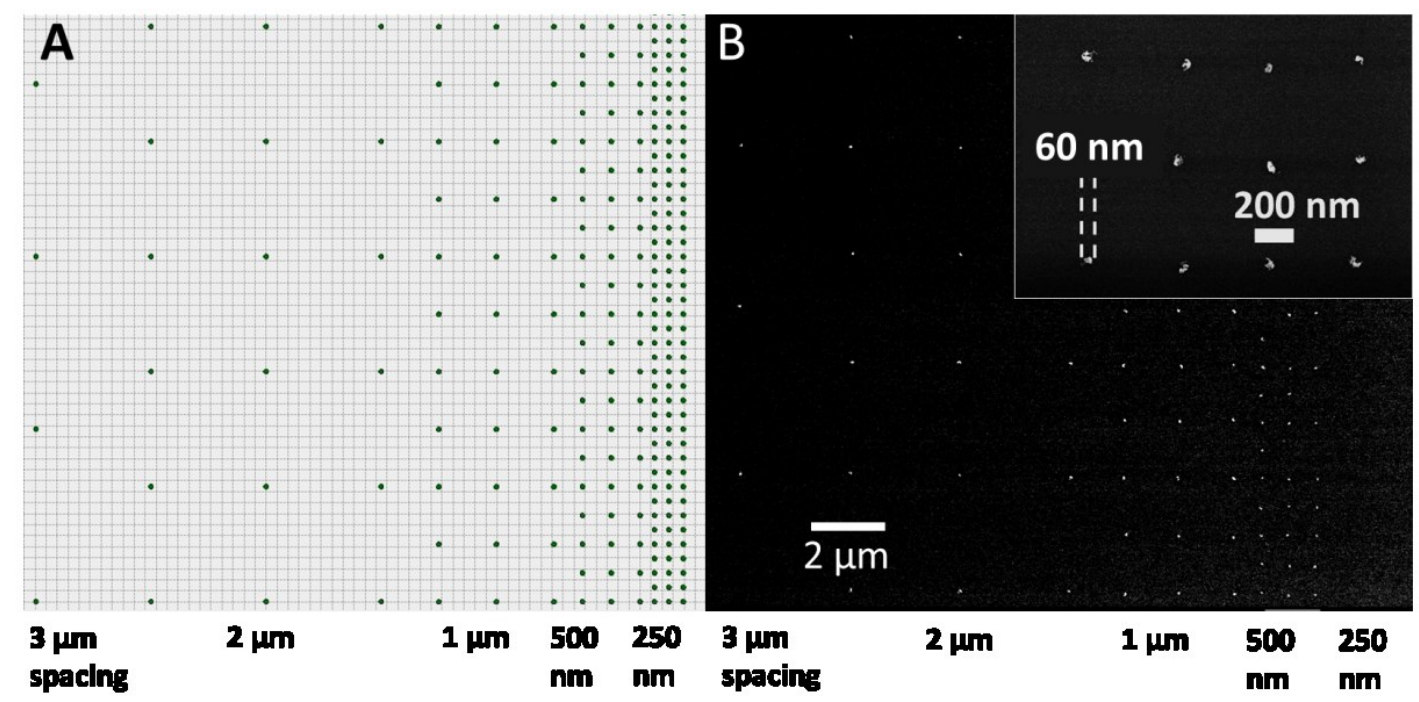

Figure 6: Proximity limit of nanoscale dot features at $45 \%$ humidity: A) Design of the InkCAD pattern composed of a gradient of dot density. Each dot is programmed with a $0.02 \mathrm{~s}$ dwell time. The dot-spacing decreases from $3 \mu \mathrm{m}$ between dots at the left to $250 \mathrm{~nm}$ between dots at the right; B) A printed dot array generated from this gradient pattern. Consistent dot features of $50 \mathrm{~nm}$ diameter were printed in most programmed positions for dot-spacings of $3 \mu \mathrm{m}, 2 \mu \mathrm{m}, 1 \mu \mathrm{m}$, and $500 \mathrm{~nm}$. The inset shows a higher magnification image of representative $60 \mathrm{~nm}$ features printed at $500 \mathrm{~nm}$ spacing. No features were deposited at a $250 \mathrm{~nm}$ spacing. This illustrates the proximity limit below which the ink transport meniscus begin to overlap with previously deposited features, preventing the definition of any pattern.

\subsection{DPN printing on soft and flexible substrates}

One of the principle advantages of the DPN liquid ink method of deposition is substrate versatility. Besides silicon wafer, the $\mathrm{H}_{2} \mathrm{PtCl}_{6} / \mathrm{EG}$ formulation was DPN printed on ITO, PDMS, gold, germanium, glass, parylene $\mathrm{C}$ and PDMS. Importantly, the $\mathrm{N}_{2}$ plasma treatment method was effective at reducing the printed precursor inks to platinum metal without damage to any of these substrates. The formulation was also printed and reduced to platinum metal upon a human hair (see supplementary information).

An interesting advantage of the in-situ reduction method is the strong adhesion between the resulting platinum feature and the substrate. Figure 7 exhibits the durability of DPN printed platinum on both ITO and PDMS after successive sonication in water and isopropanol. Micron-scale features were used to allow characterization, by optical microscopy, of feature morphology between each of many washing steps. The grid of platinum dots printed on PDMS is unchanged after 1 hour bath sonication in water. The grid is still unchanged after a further 48 hour immersion and 1 hour sonication in isopropanol, though the PDMS substrate itself has begun to degrade. The grid of platinum dots on ITO remained unchanged after both sonication steps. A grid of platinum dots on silicon, however, did show some degradation with some features destroyed by each sonication step (not shown). The stronger adhesion on soft or rough substrates (PDMS and ITO) than on flat, rigid substrates $\left(\mathrm{Si} / \mathrm{SiO}_{2}\right)$, suggests that mechanical interlocking may be the origin of the attachment. Further work is required to understand the origin of the attachement, and also to investage how adhesion scales for nanoscale features. The strong attachment of platinum nanoparticles synthesized by in-situ thermal reduction of dropcast $\mathrm{H}_{2} \mathrm{PtCl}_{6} / \mathrm{EG}$ films has previously been reported[32,42], where 
the adhesion mechanism was attributed to the high surface energy of the platinum nanoparticles.

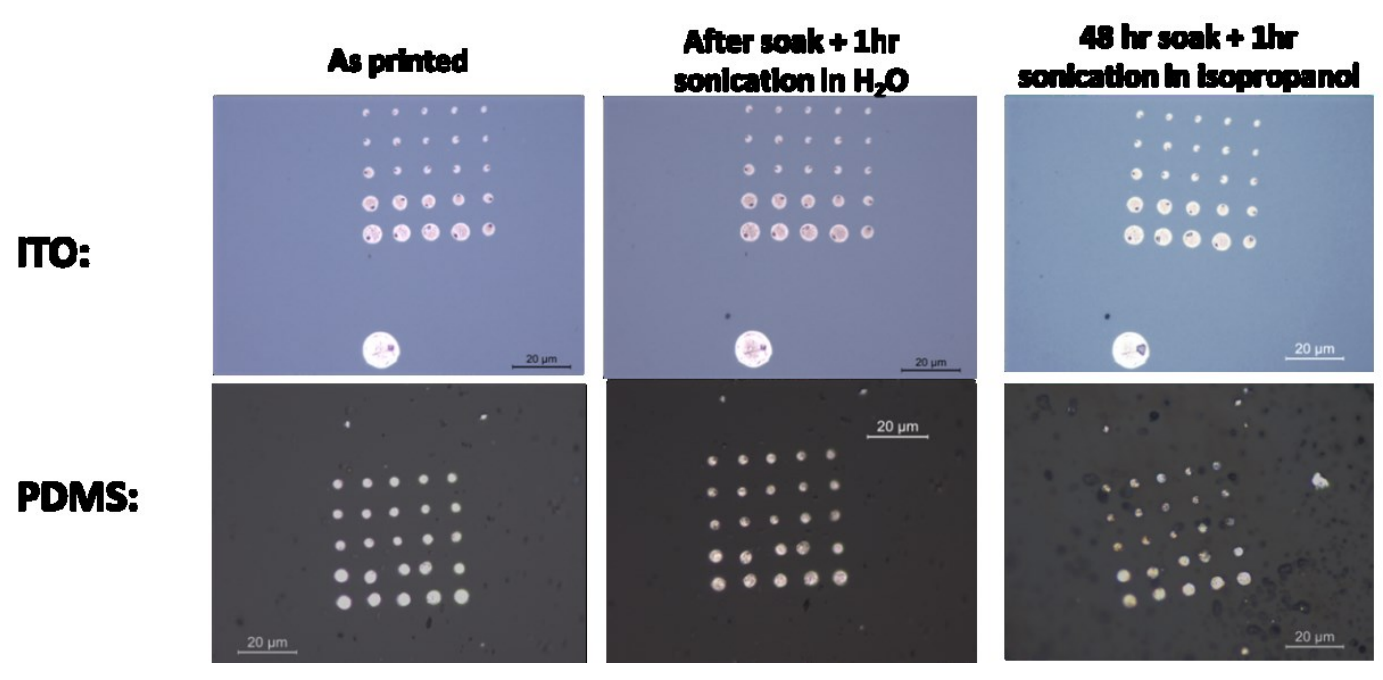

Figure 7: Solvent and sonication resistance of platinum features. Optical microscopy of platinum dots on ITO and PDMS illustrate feature survival against extensive sonication in both water and isopropanol.

\subsection{Mapping electrochemical activity of platinum features by scanning electrochemical microscopy (SECM)}

Scanning electrochemical microscopy (SECM) uses a scanning micro-electrode tip to measure local electrochemical activity[43]. In order to confirm the electrochemical activity of DPN printed platinum, SECM scans were performed on platinum dots on an ITO substrate. Figure 8 shows AFM scans of DPN printed Pt dot arrays (i.e. after plasma reduction) and the corresponding SECM current maps. Electrochemical activity is generally much higher around the printed platinum features than on the surrounding ITO substrate. Given the very small surface profile of the Pt features $(<100 \mathrm{~nm})$ compared to the tipsubstrate distance (i.e. $3 \mu \mathrm{m}$ ) it is reasonable to assume the variation in feedback current is only due to the electrochemical reactivity of the substrate and surface profile has no influence. A remarkably higher feedback current at Pt features indicates enhanced charge transfer properties at $\mathrm{Pt}$ features compared to the ITO surface.

When two micro-features are placed close enough together (i.e. closer than the Debye length-about ten times the feature diameter), their electric double layers can overlap, causing them to act like one large electrode. The threshold for this capacitive overlap of neighbouring Pt features can be visualized by SECM. The dot arrays printed at a pitch of $5 \mu \mathrm{m}$ and $10 \mu \mathrm{m}$ (Figure $8 \mathrm{~A}$ and B respectively) act as single, square shaped electrodes of dimension $50 \times 50 \mu \mathrm{m}$, despite being composed of much smaller individual Pt features. The SECM scan of the $20 \mu \mathrm{m}$ pitch Pt dot array, however, shows nine current peaks, each corresponding to a single DPN printed dot (Figure $8 \mathrm{C}$ and D). The overlap in signals from neighbouring $\mathrm{Pt}$ features may also be due in part the relatively large size of our microelectrode which is incapable of differentiating between features much smaller than its own size $(10 \mu \mathrm{m})$. Future work will characterise the electrochemical activity of nanoscale printed platinum features utilising an SECM nanoelectrode. 


\section{AFM topography SECM current map}
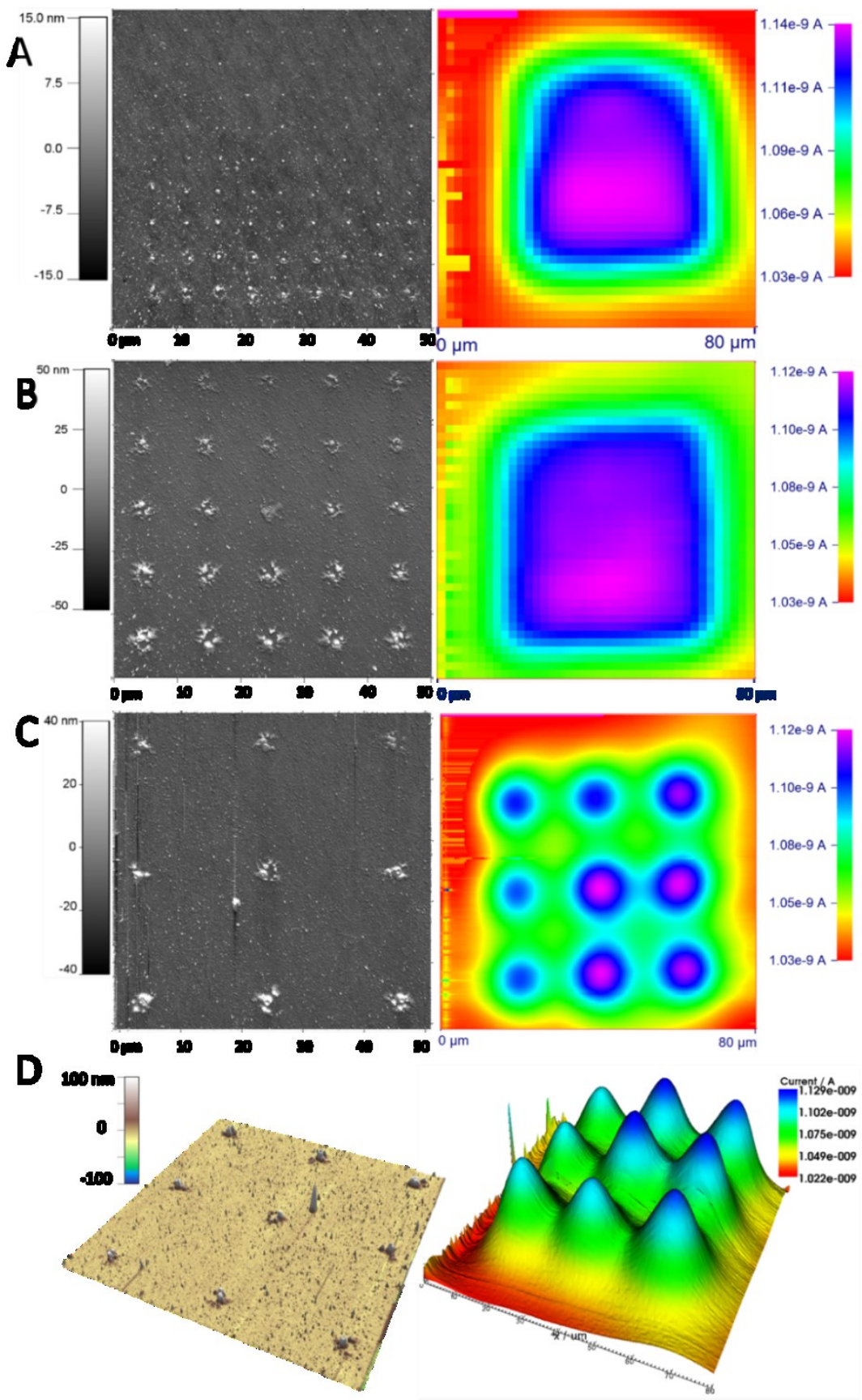

Figure 8: AFM topography and SECM current maps of Pt metal dot arrays on ITO glass. (Note: AFM images are 50 × $50 \mu \mathrm{m}$ scans, while SECM images are $80 \times 80 \mu \mathrm{m}$ scans): A) AFM topography (left hand image) and SECM current maps (right hand image) for $81 \mathrm{Pt}$ features of $2 \mu \mathrm{m}$ diameter at a $5 \mu \mathrm{m}$ pitch. The SECM current map shows the square-shaped outline of the whole array as the current signals overlap. B) AFM topography (left hand image) and SECM current map (right hand image) for 25 Pt features of $\sim 5 \mu \mathrm{m}$ diameter at a $10 \mu \mathrm{m}$ pitch. Again, the ratio of pitch to feature diameter is small and so the electrodes appear as on large electrode in the SECM scan; C) AFM topography (left hand image) and SECM current map (right hand image) for 9 Pt features of $\sim 5 \mu \mathrm{m}$ diameter at a $20 \mu \mathrm{m}$ pitch. In this case the SECM detects 
distinct peaks corresponding to each printed platinum feature. D) 3D rendered AFM topography and SECM current map for the $20 \mu \mathrm{m}$ pitch dot array.

\section{Conclusions}

A strategy has been developed for depositing arbitrary nanoscale patterns of platinum on insulating substrates using DPN. The liquid ink formulation is composed of the platinum precursor $\mathrm{H}_{2} \mathrm{PtCl}_{6}$ in ethylene glycol, which acts as both ink carrier and reducing agent. Reduction of the precursor to metal was facilitated under mild, non-destructive conditions via a novel nitrogen plasma treatment method, as supported by EDS and XRD measurements. The DPN deposition rate was dependent on the volume of ink on the cantilever, with minimum feature size of $\sim 60 \mathrm{~nm}$ diameter on silicon. The methodology was versatile enough to print on a range of flexible substrates including PDMS and ITO with strong attachment of the platinum patterns. We have confirmed the high electrochemical activity of microscale printed Pt by SECM, however higher resolution techniques (such as SECM-AFM and conductive AFM) will be required for characterisation of nanoscale features. Due to dewetting of the ink on the substrate, continuous lines could not be fabricated by this approach, limiting its application in the printing of current carrying wires. Further work could investigate the selective functionalization of a substrate to control wetting, and thus confine the ink to stable line patterns as has been used to generate 'nanostripes' of liquid ethanol on silicon[44].

Several DPN strategies for printing gold features on insulating substrates have been developed, however strategies for printing platinum are lacking. The simplicity of our approach and the mild nature of the reduction strategy allow for the versatility to pattern on a wide variety of substrates. To demonstrate this, the $48 \% \mathrm{H}_{2} \mathrm{PtCl}_{6} / \mathrm{EG}$ ink was also DPN printed on a strand of human hair (Supplementary Information). Nitrogen plasma treatment reduced the printed features to platinum in situ, without damage to the hair.

We have illustrated the development of a new nanoscale platinum printing strategy, however in this preliminary work some of the characterisation is as yet limited to micro-scale features. The scaling of the catalytic, mechanical and electrical properties of platinum features as they transition from micro- to nano-scale is particularly interesting. The implementation of nanoscale characterisation techniques, in particular various scanning probe methods, will allow us to study these effects on DPN printed nanoscale features.

\section{Acknowledgments}

The authors are grateful for the continued financial support of the Australian Research Council under the Australian Federation and Laureate Fellowships of Prof Gordon Wallace, the Australian Research Fellowship of Assoc. Prof. Michael Higgins and the QEII Fellowship of Assoc. Prof. Simon Moulton. The DPN system is gratefully provided via the Australian National Fabrication Facility (ANFF), Materials Node. The authors acknowledge use of facilities within the UOW Electron Microscopy Centre. 


\section{Supplementary Information}

\subsection{Probe hydrophilicity}

As shown in Figure 9 (A) the non-functionalised (hydrophilic) cantilever displayed a relative decrease of $80 \%$ of its ink mass within 10 minutes after inking. The hydrophobic cantilever showed a decrease of only $10 \%$ ink mass over the same time period. This smaller decrease was not the result of ink diffusion over the chip, but rather of EG evaporation. The rate of evaporation suggested the ink would maintain viability for a period of at least an hour. However, it must be noted that the gradual evaporation of EG from the ink would lead to a general increase in metal precursor concentration over the course of long printing experiments.
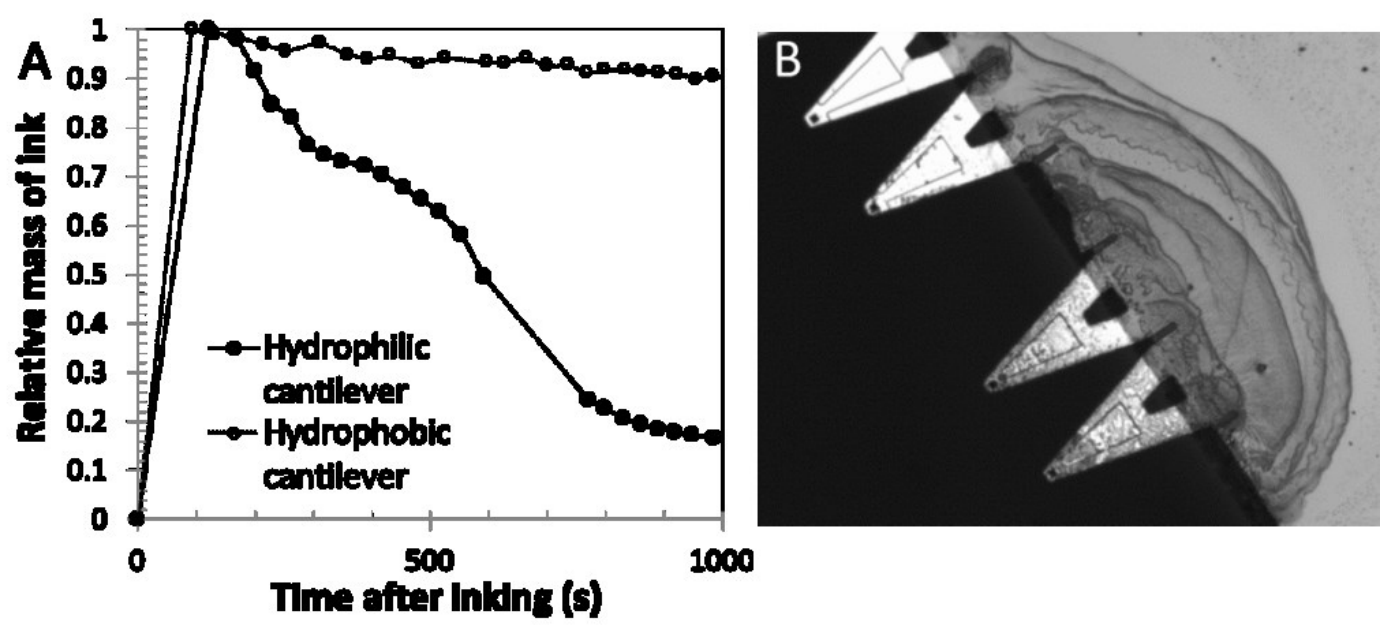

Figure 9: Spreading of the metal precursor ink over the cantilever chip dramatically effects printing lifetime: $A)$ Measurements of the resonance frequency of cantilevers inked with $40 \%$ wt $\mathrm{H}_{2} \mathrm{PtCl}_{6}$ in EG over time (without printing). The change in resonant frequency has been converted to a change in ink mass via Hooke's law. A nonfunctionalised cantilever lost $80 \%$ of ink mass whereas a cantilever functionalised to be hydrophobic (with octadecyltrimethoxysilane) lost only 10\% of its ink mass over 15 minutes. B) The rapid decrease in mass of ink on the hydrophilic (non-functionalised) cantilever was caused by the spreading of the ink from the cantilever itself on to the back of the cantilever chip.

\subsection{Printing a precursor solution and reducing to platinum metal in situ on a human hair}

In order to demonstrate the versatility of our platinum precursor ink formulation, and the mild conditions under which reduction of the printed features takes place, we DPN printed a single platinum feature on a strand of human hair. 

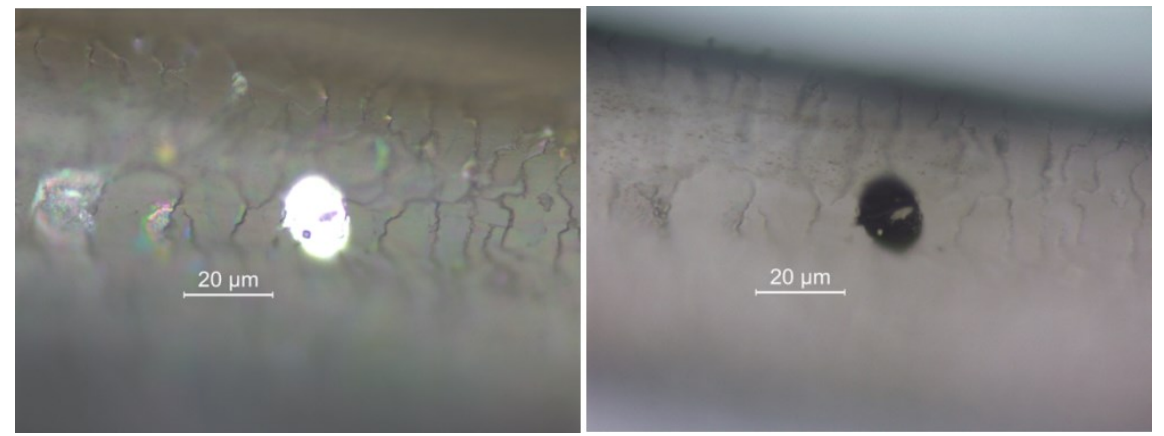

Figure 10: A single dot of $48 \%$ wt $\mathrm{H}_{2} \mathrm{PtCl}_{6}$ solution DPN printed onto a human hair after treatment with $\mathrm{N}_{2}$ plasma (10 minutes). A) Bright field optical microscopy shows the bright silvery/white colour of the platinum feature after plasma assisted reduction; B) Transmitted light optical microscopy shows the opacity of the dense metal contrasted with the relative transparency of the hair.

\subsection{Line writing}

DPN line writing of $\mathrm{H}_{2} \mathrm{PtCl}_{6} / \mathrm{EG}$ ink was performed by bringing inked pens into contact with the substrate and moving laterally at a range of write-speeds $\left(100 \mu \mathrm{m} \mathrm{s}^{-1}\right.$ to $\left.1 \mu \mathrm{m} \mathrm{s}^{-1}\right)$. Rather than forming continuous lines of precursor, the ink was only deposited as a final droplet punctuating the line, indicating where the tip retracted from the substrate. Error! Reference source not found. shows an SEM micrograph of a line pattern attempted with the $10 \%$ ink. Although faint vertical lines are visible in the image, these lines faded after a few moments of SEM imaging. This indicates the lines were most likely composed of residual solvent deposited during the DPN process. A similar phenomenon observed during the DPN linewriting of a PEDOT:PSS has previously been described[22].

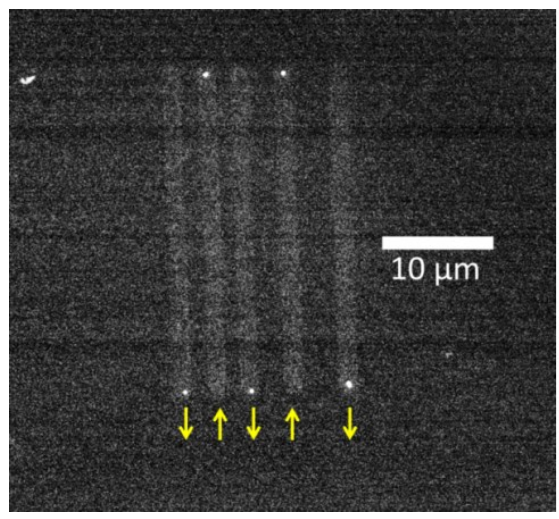

Figure 11: SEM micrograph of attempted DPN lines. Each line was drawn in the direction indicated by the arrow beneath it. The lines were drawn at write speeds of $100 \mu \mathrm{m} \mathrm{s}^{-1}, 10 \mu \mathrm{m} \mathrm{s}^{-1}, 5 \mu \mathrm{m} \mathrm{s}^{-1}, 2 \mu \mathrm{m} \mathrm{s}^{-1}$, and $1 \mu \mathrm{m} \mathrm{s}^{-1}$ respectively. A single platinum dot was formed at the end of each line where the tip retracted from the substrate. The lines exhibit very poor contrast compared with the punctuating dots, and SEM imaging was only possible for several minutes before the lines faded from view entirely; this indicates the lines were most likely composed of residual solvent deposited during the DPN process and not platinum itself. 


\subsection{Electrical conductivity}

The electrical conductivity of the DPN printed platinum was confirmed using a two point electrical measurement. The current voltage response of the deposited feature exhibited ohmic behaviour over a voltage range of $-10 \mathrm{~V}$ to $+10 \mathrm{~V}$. The resistance of the patterned feature was measured at $29 \mathrm{kOhm}$. From the topographical measurements, the conductivity was determined to be about $340 \mathrm{~S} / \mathrm{m}$, though a true conductivity value is difficult to extract from this 2 point probe measurement, because the contact resistance of the system is unknown. This value is still several orders of magnitude below the conductivity of bulk platinum. We suggest this low conductivity value may arise from contact resistance between the printed feature and the gold micro-electrode contacts, and the micro-porous nature of the platinum feature. The resistance did not change after annealing at $100{ }^{\circ} \mathrm{C}, 200{ }^{\circ} \mathrm{C}$ and 300 ${ }^{\circ} \mathrm{C}$, suggesting the poor conductivity was not due to incomplete reduction of the ink during plasma treatment. Although such high resistance is not amenable for applications such as solid-state micro- or nano-wires, the high localized electrochemical activity of the printed platinum material is far more promising (section 3.5.).

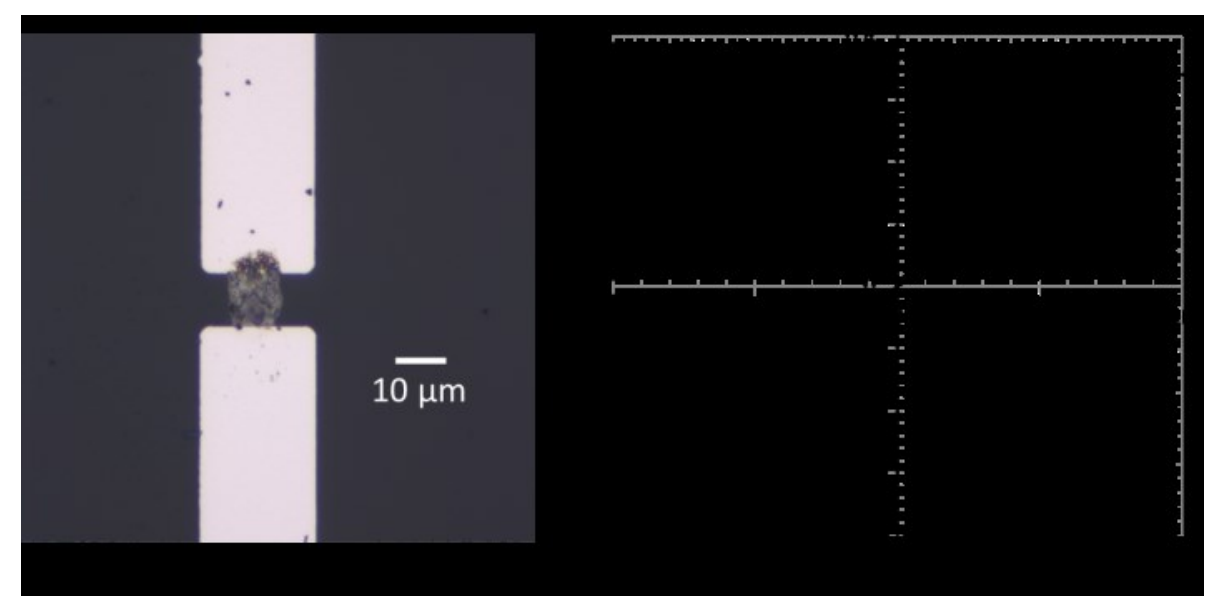

Figure 12: Confirming the electrical conductivity of DPN printed platinum; A) bright field optical micrograph of a DPN printed platinum spot connecting two planar electrodes (fabricated by photolithography); B) The current voltage response of the deposited feature confirms the ohmic behaviour of the platinum. The resistance of the patterned feature was measured at $29 \mathrm{kOhm}$ and the conductivity at $342 \mathrm{~S} / \mathrm{m}$. The resistance did not change after annealing at $100{ }^{\circ} \mathrm{C}, 200{ }^{\circ} \mathrm{C}$ and $300{ }^{\circ} \mathrm{C}$.

\section{References}

[1] $\quad \mathrm{Hu}$ J and Yu M-F 2010 Meniscus-confined three-dimensional electrodeposition for direct writing of wire bonds. Science (New York, N.Y.) 329 313-6

[2] Yang M, Qu F, Lu Y, He Y, Shen G and Yu R 2006 Platinum nanowire nanoelectrode array for the fabrication of biosensors. Biomaterials 27 5944-50

[3] Komanicky V, Iddir H, Chang K, Menzel A, Karapetrov G, Hennessy D, Zapol P and You H 2009 Shape-dependent activity of platinum array catalyst. Journal of the American Chemical Society 131 5732-3

[4] Cogan S F 2008 Neural stimulation and recording electrodes. Annual review of biomedical engineering 10 275-309 
[5] Gates B D, Xu Q, Stewart M, Ryan D, Willson C G and Whitesides G M 2005 New approaches to nanofabrication: molding, printing, and other techniques. Chemical reviews 105 1171-96

[6] Wong W S and Salleo A 2009 Flexible Electronics vol 11 (Boston, MA: Springer US)

[7] Rehfeldt F, Engler A J, Eckhardt A, Ahmed F and Discher D E 2007 Cell responses to the mechanochemical microenvironment--implications for regenerative medicine and drug delivery. Advanced drug delivery reviews 59 1329-39

[8] Wallace G G, Moulton S E and Clark G M 2009 Applied physics. Electrode-cellular interface. Science (New York, N.Y.) 324 185-6

[9] Moulton S E, Higgins M J, Kapsa R M I and Wallace G G 2012 Organic Bionics: A New Dimension in Neural Communications Advanced Functional Materials 22 2003-14

[10] Okinaka Y and Wolowodiuk C 1990 Electroless Plating Of Platinum Group Metals Electroless Plating (William Andrew Publishing) pp 421-40

[11] Liu Z, Su Y and Varahramyan K 2005 Inkjet-printed silver conductors using silver nitrate ink and their electrical contacts with conducting polymers Thin Solid Films 478275 - 279

[12] Chang H-J, Tsai M-H, Hwang W-S, Wu J-T, Hsu S L-C and Chou H-H 2012 Application of Silver Nitrate Solution and Inkjet Printing in the Fabrication of Microstructural Patterns on Glass Substrates The Journal of Physical Chemistry C 116 4612-20

[13] Walker S B and Lewis J a 2012 Reactive silver inks for patterning high-conductivity features at mild temperatures. Journal of the American Chemical Society 134 1419-21

[14] Park J-U, Hardy M, Kang S J, Barton K, Adair K, Mukhopadhyay D K, Lee C Y, Strano M S, Alleyne A G, Georgiadis J G, Ferreira P M and Rogers J a 2007 High-resolution electrohydrodynamic jet printing. Nature materials 6 782-9

[15] Xie X N, Chung H J, Bandyopadhyay D, Sharma A, Sow C H and Wee A T S 2008 Micro/nanoscopic patterning of polymeric materials by atomic force microscope assisted electrohydrodynamic nanolithography Journal of Applied Physics 103024307

[16] Wu B, Ho A, Moldovan N and Espinosa H D 2007 Direct deposition and assembly of gold colloidal particles using a nanofountain probe. Langmuir : the ACS journal of surfaces and colloids 23 9120-3

[17] Fang A, Dujardin E and Ondarçuhu T 2006 Control of droplet size in liquid nanodispensing. Nano letters 6 2368-74

[18] Piner R D 1999 “Dip-Pen” Nanolithography Science 283 661-3

[19] Lee K-B, Park S-J, Mirkin C a, Smith J C and Mrksich M 2002 Protein nanoarrays generated by dip-pen nanolithography. Science (New York, N.Y.) $2951702-5$

[20] Demers L M, Ginger D S, Park S-J, Li Z, Chung S-W and Mirkin C A 2002 Direct patterning of modified oligonucleotides on metals and insulators by dip-pen nanolithography. Science (New York, N.Y.) 296 1836-8 
[21] Zhang H and Mirkin C A 2004 DPN-Generated Nanostructures Made of Gold, Silver, and Palladium Chemistry of Materials 16 1480-4

[22] Nakashima H, Higgins M J, O’Connell C, Torimitsu K and Wallace G G 2012 Liquid deposition patterning of conducting polymer ink onto hard and soft flexible substrates via dippen nanolithography. Langmuir : the ACS journal of surfaces and colloids 28 804-11

[23] O’Connell C D, Higgins M J, Nakashima H, Moulton S E and Wallace G G 2012 Vapor phase polymerization of EDOT from submicrometer scale oxidant patterned by dip-pen nanolithography. Langmuir : the ACS journal of surfaces and colloids 28 9953-60

[24] Wagner M, O’Connell C D, Harman D G, Sullivan R, Ivaska A, Higgins M J and Wallace G G 2013 Synthesis and optimization of PEDOT:PSS based ink for printing nanoarrays using Dip-Pen Nanolithography Synthetic Metals 181 64-71

[25] Basnar B and Willner I 2009 Dip-pen-nanolithographic patterning of metallic, semiconductor, and metal oxide nanostructures on surfaces. Small (Weinheim an der Bergstrasse, Germany) 5 $28-44$

[26] Suryavanshi A P and Yu M-F 2007 Electrochemical fountain pen nanofabrication of vertically grown platinum nanowires Nanotechnology 18105305

[27] Crocker Chicago IL (US) P V J R, Demers Evanston IL (US) L and Amro Skokie IL (US) N A 2004 Processes for fabricating conductive patterns using nanolithography as a patterning tool $\mathbf{1 0 6 4 7 4 3 0}$

[28] Chai J, Huo F, Zheng Z, Giam L R, Shim W and Mirkin C a 2010 Scanning probe block copolymer lithography. Proceedings of the National Academy of Sciences of the United States of America 107 20202-6

[29] Wang H, Nafday O A, Haaheim J R, Tevaarwerk E, Amro N A, Sanedrin R G, Chang C, Ren F and Pearton S J 2008 Toward conductive traces: Dip Pen Nanolithography® of silver nanoparticle-based inks Applied Physics Letters 93143105

[30] Schweizer A E and Kerr G T 1978 Thermal decomposition of hexachloroplatinic acid Inorganic Chemistry 17 2326-7

[31] Komarneni S, Li D, Newalkar B, Katsuki H and Bhalla A S 2002 Microwave-Polyol Process for Pt and Ag Nanoparticles Langmuir 18 5959-62

[32] Cho S J and Ouyang J 2011 Attachment of Platinum Nanoparticles to Substrates by Coating and Polyol Reduction of A Platinum Precursor The Journal of Physical Chemistry C 115 8519-26

[33] Larcher D and Patrice R 2000 Preparation of Metallic Powders and Alloys in Polyol Media: A Thermodynamic Approach Journal of Solid State Chemistry 154 405-11

[34] Jaramillo T F, Baeck S, Cuenya B R and McFarland E W 2003 Catalytic activity of supported Au nanoparticles deposited from block copolymer micelles. Journal of the American Chemical Society 125 7148-9

[35] Liu G, Eichelsdoerfer D J, Rasin B, Zhou Y, Brown K a, Liao X and Mirkin C a 2013 Delineating the pathways for the site-directed synthesis of individual nanoparticles on surfaces. Proceedings of the National Academy of Sciences of the United States of America $110887-91$ 
[36] Blin B, Fievet F, Beaupere D and Figlarz M 1989 Double oxidation of glycol ethylene in a new process of powder metallurgy elaboration New journal of chemistry 13 67-72

[37] O’Connell C D, Higgins M J, Moulton S E and Wallace G G 2013 Liquid deposition from an atomic force microscope tip: Deposition monitoring, droplet geometry and control of featuresize Submitted

[38] Weeks B, Noy A, Miller A and De Yoreo J 2002 Effect of Dissolution Kinetics on Feature Size in Dip-Pen Nanolithography Physical Review Letters 88 1-4

[39] Rozhok S, Piner R and Mirkin C a. 2003 Dip-Pen Nanolithography: What Controls Ink Transport? The Journal of Physical Chemistry B 107 751-7

[40] O’Connell C D, Sullivan R, Higgins M J, Moulton S E and Wallace G G 2013 Ink-on-probe hydrodynamics in atomic force microscope deposition of liquid inks Submitted

[41] Weeks B L, Vaughn M W and Deyoreo J J 2005 Direct imaging of meniscus formation in atomic force microscopy using environmental scanning electron microscopy. Langmuir : the ACS journal of surfaces and colloids 21 8096-8

[42] Sun K, Fan B and Ouyang J 2010 Nanostructured Platinum Films Deposited by Polyol Reduction of a Platinum Precursor and Their Application as Counter Electrode of DyeSensitized Solar Cells The Journal of Physical Chemistry C 114 4237-44

[43] Amemiya S, Bard A J, Fan F-R F, Mirkin M V and Unwin P R 2008 Scanning electrochemical microscopy. Annual review of analytical chemistry (Palo Alto, Calif.) 195 131

[44] Checco A, Gang O and Ocko B 2006 Liquid Nanostripes Physical Review Letters 96056104 